\title{
ИССЛЕДОВАНИЕ НИЗКОТЕМПЕРАТУРНОИ АДСОРБЦИИ АЗОТА НА ПОВЕРХНОСТИ ОКСИДОВ ГАЛЛИЯ И ИНДИЯ
}

\author{
(Представил О. Эйзен)
}

Известно, что оксиды некоторых металлов III группы периодической системы, в частности $\mathrm{Al}_{2} \mathrm{O}_{3}, \mathrm{Ga}_{2} \mathrm{O}_{3}$ и $\mathrm{In}_{2} \mathrm{O}_{3}$, хорошие катализаторы и адсорбенты, но их свойства, кроме оксида алюминия изучены мало.

В данной работе исследовалась низкотемпературная адсорбция азота на $\alpha$ - и $\beta$-модификациях оксидов галлия и на оксиде индия.

$\alpha$-Модификация оксида галлия со структурой корунда была синтезирована прокаливанием нитрата галлия ос. ч. при температуре 400$450{ }^{\circ} \mathrm{C}$. Полученный оксид промывали дистиллированной водой до прекращения реакции на $\mathrm{NO}_{3}^{-}$и высушивали при температуре $120^{\circ} \mathrm{C}$. Исследовали два образца $\alpha$-модификации оксида галлия: один - сразу после его изготовления, другой - после годичного хранения в нормальных лабораторных условиях.

Структура $\alpha$ - и $\beta$-модификаций оксида галлия была установлена рентгеноструктурным анализом. Моноклинная $\beta$-модификация оксида галлия и оксид индия (кристаллизуется в кубической решетке) были ос. ч.

До измерения все адсорбенты подвергали дегазации в течение 24 ч в потоке гелия при температуре $250^{\circ} \mathrm{C}$. Время дегазации свежеприготовленной $\alpha$-модификации оксида галлия увеличивали еще вдвое, т. е. 48 ч, чтобы изучить влияние длительного нагревания на свойства ее поверхности.

Количество адсорбированного азота $\mathrm{V}_{\mathrm{a}}$ при температуре $-196^{\circ} \mathrm{C}$ измеряли в пределах относительных давлений $p / p_{0}$ от 0,018 до 0,545 с помощью хроматографической установки «Сорбтометр ЕМ-31». На основе экспериментальных данных строили изотермы низкотемпературной адсорбции азота (рис. 1).

Все полученные изотермы, согласно классификации Брунауэра ['], относятся K II типу и имеют довольно длинный прямолинейный участок. Начальная точка этого прямолинейного участка, обозначенная на рис. 1 буквой «B» $\left.{ }^{1}\right]$, указывает на окончание заполнения монослоя. Поэтому адсорбция в точке $B\left(V_{B}\right)$ равна емкости монослоя $\left(V_{m}\right)$. Значение $V_{B}$ для очень многих систем хорошо согласуется со значением $V_{m}$, рассчитанным по уравнению БЭТ:

$$
\frac{p}{V_{a}\left(p_{0}-p\right)}=\frac{1}{V_{m} \cdot C}+\frac{C-1}{V_{m} \cdot C} \cdot \frac{p}{p_{0}}
$$

где $C$ - постоянная, связанная с теплотой адсорбции.

В данной работе емкость монослоя азота на исследованных оксидах определяли в точке $B$ и графически вычисляли по уравнению БЭТ (1) в линейной области графика до относительного давления 0,3 . Кроме того, 


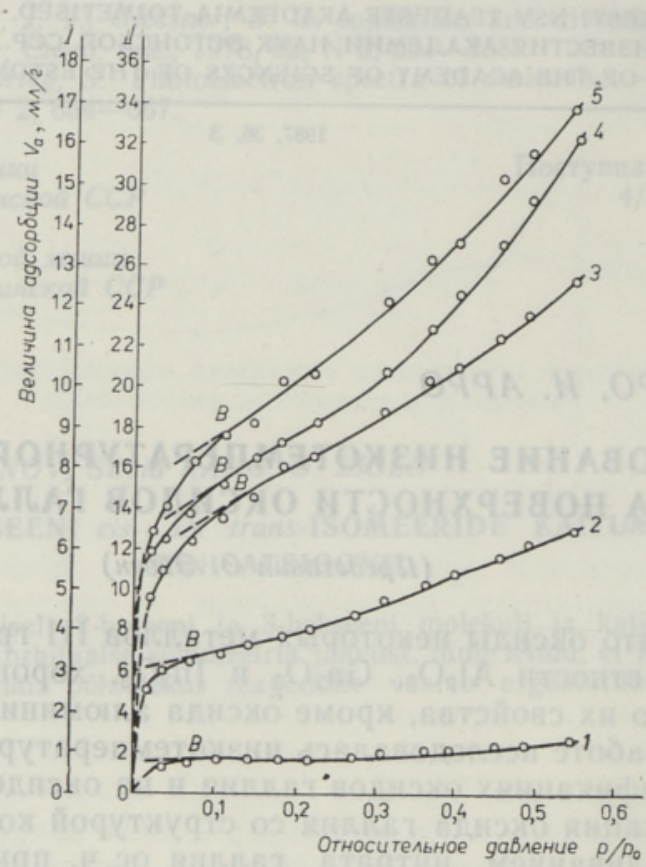

Рис. 1. Изотермы адсорбции азота при $-196^{\circ} \mathrm{C}$ на $\mathrm{In}_{2} \mathrm{O}_{3}(\mathrm{I}, 1) ; \beta-\mathrm{Ga}_{2} \mathrm{O}_{3}$ (I, 2); $\alpha-\mathrm{Ga}_{2} \mathrm{O}_{3}$ годичной выдержки (II, 3 ); свежеприготовленном $\alpha-\mathrm{Ga}_{2} \mathrm{O}_{3}$, время дегазацин 48 ч (II, 4); свежеприготовленном $\alpha-\mathrm{Ga}_{2} \mathrm{O}_{3}$, время дегазации 24 ч (II, 5).

по уравнению БЭТ определяли постоянную $C$. С использованием полученных значений емкостей монослоя вычисляли удельные поверхности исследованных оксидов по формуле:

$$
S=V \cdot \omega_{0},
$$

где $S$ - удельная поверхность, м $^{2} / r ; V-$ емкость монослоя, мл/г; $\omega_{0}-$ площадь, покрываемая монослоем $1 \mathrm{~cm}^{3}$ азота, которая была принята равной $4,39 \mathrm{~m}^{2}\left[{ }^{2}\right]$.

Сравнение полученных результатов показало, что значение $V_{B}$ и $V_{m}$ довольно хорошо согласуются между собой для всех исследованных оксидов (табл. 1). Это объясняется резким изгибом изотерм, позволяю-

Таблица 1

\begin{tabular}{|c|c|c|c|c|c|c|}
\hline \multirow{3}{*}{ Оксид } & \multirow{2}{*}{\multicolumn{2}{|c|}{$\begin{array}{c}\text { Емкость монослоя, } \\
\text { мл/г }\end{array}$}} & \multirow{3}{*}{ C } & \multicolumn{3}{|c|}{ Удельная поверхность, м²/r $^{2}$} \\
\hline & & & & \multirow{2}{*}{$S_{B}$} & \multirow{2}{*}{$S_{\text {Бэт }}$} & \multirow{2}{*}{$S_{t}$} \\
\hline & $V_{B}$ & $V_{m}$ & & & & \\
\hline $\mathrm{In}_{2} \mathrm{O}_{3}$ & 0,79 & 0,74 & 192 & 3,9 & 3,2 & 3,2 \\
\hline$\beta-\mathrm{Ga}_{2} \mathrm{O}_{3}$ & 3,3 & 3,3 & 100 & 14,5 & 14,5 & 14,9 \\
\hline $\begin{array}{l}\alpha-\mathrm{Ga}_{2} \mathrm{O}_{3} \\
\text { (годичной выдержки) }\end{array}$ & 13,0 & 12,9 & 111 & 57,1 & 56,6 & 55,7 \\
\hline $\begin{array}{l}\alpha-\mathrm{Ga}_{2} \mathrm{O}_{3} \\
\text { (свежеприготовленный, } \\
\text { время дегазации } 24 \text { ч) }\end{array}$ & 16,6 & 16,8 & 99 & 72,9 & 73,8 & 73,1 \\
\hline$\alpha-\mathrm{Ga}_{2} \mathrm{O}_{3}$ & 14,8 & 14,7 & 96 & 65,0 & 64,5 & 63,4 \\
\hline
\end{tabular}

(свежеприготовленный, время дегазации 48 ч) 
щим легко определить точку $B$, и их положением в области давлений, соответствующих линейному участку графика БЭТ [3].

$\alpha$-Модификация оксида галлия, приготовленная разложением нитрата галлия, имеет значительно бо́льшую удельную поверхность, чем $\beta$-модификация. При хранении в нормальных лабораторных условиях и при нагревании удельная поверхность $\alpha$-модификации оксида галлия заметно снижалась (примерно до 25\%). Такое изменение удельной поверхности в процессе нагревания необходимо учитывать при проведении адсорбционных исследований. Поэтому в настоящей работе более подробно исследовали зависимости удельной поверхности свежеприготовленного $\alpha-\mathrm{Ga}_{2} \mathrm{O}_{3}$ от температуры и времени нагревания (табл. 2).

Таблища 2

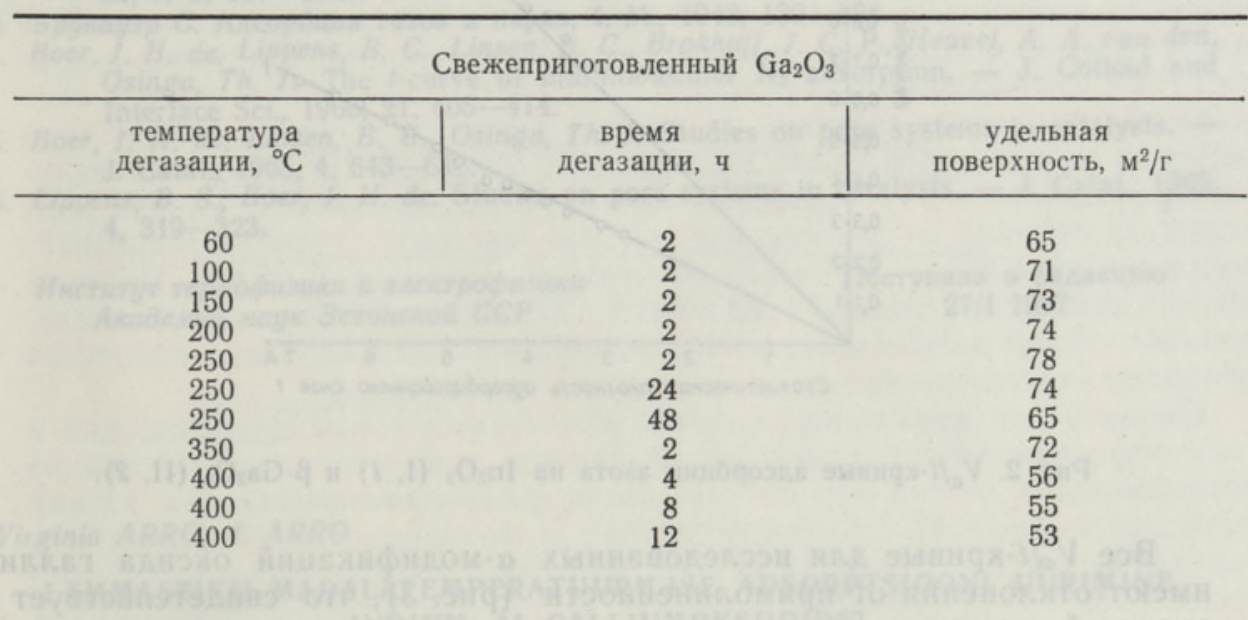

Из данных табл. 2 видно, что подходящие температуры дегазации $\alpha-\mathrm{Ga}_{2} \mathrm{O}_{3}$ находятся в пределах от 150 до $250^{\circ} \mathrm{C}$. Если в интервале указанных температур нагревание длится меньше 24 ч, то заметных изменений в величине удельной поверхности нет. Уменьшение удельной поверхности примерно на $10 \%$ наблюдается при нагревании адсорбента при $250{ }^{\circ} \mathrm{C}$ до 48 ч. Использование более высоких температур $\left(400^{\circ} \mathrm{C}\right)$ для дегазации $\alpha-\mathrm{Ga}_{2} \mathrm{O}_{3}$ вызывает уже в течение сравнительно короткого времени (4 ч) уменьшение величины удельной поверхности примерно на $25 \%$.

Для получения информации о пористости исследованных адсорбентов использовали $t$-метод Липпинса $\left[{ }^{4}\right]$, так как полученные нами значения константы $C$ уравнения БЭТ для оксидов галлия и индия (табл. 1) находятся в тех же пределах, что и установленные в [ $\left.{ }^{4}\right]$.

Для вычисления статистической плотности $t$ адсорбированного слоя пользовались уравнением [5]

$$
t=\left(\frac{13,99}{0,034-\lg p / p_{0}}\right)^{1 / 2} .
$$

При отсутствии на поверхности адсорбента микропор и капилляров зависимость $V_{a} / t$ является линейной и кривая пересекает нулевую точку. Величина удельной поверхности может быть вычислена тогда по тангенсу угла наклона прямой по формуле

$$
V_{a}=\frac{S}{15,47} \cdot t
$$


Кривая зависимости $V_{a} / t$ для оксида индия и $\beta$-модификации оксиддаa галлия пересекает нулевую точку и является прямолинейной во всей исследованной области (рис. 2). Вычисленные по тангенсу угла наклона $V_{a} / t$-кривой удельные поверхности $S_{t}$ этих оксидов (табл. 1 ) отличаются

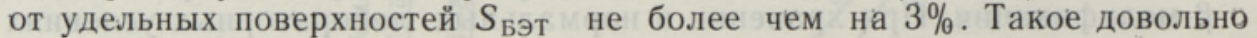
хорошее совпадение подтверждает правильность выбора $t$-кривой.

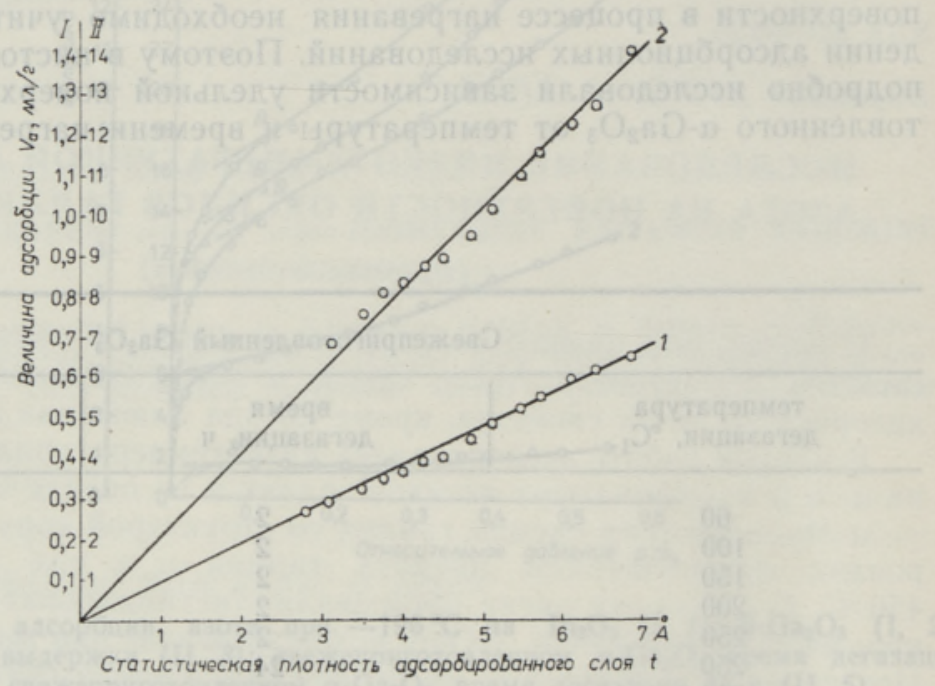

Рис. 2. $V_{a} / t$-кривые адсорбции азота на $\operatorname{In}_{2} \mathrm{O}_{3}(\mathrm{I}, 1)$ и $\beta-\mathrm{Ga}_{2} \mathrm{O}_{3}(\mathrm{II}, 2)$.

Bce $V_{a} / t$-кривые для исследованных $\alpha$-модификаций оксида галлия имеют отклонения от прямолинейности (рис. 3), что свидетельствует о пористой структуре образцов.

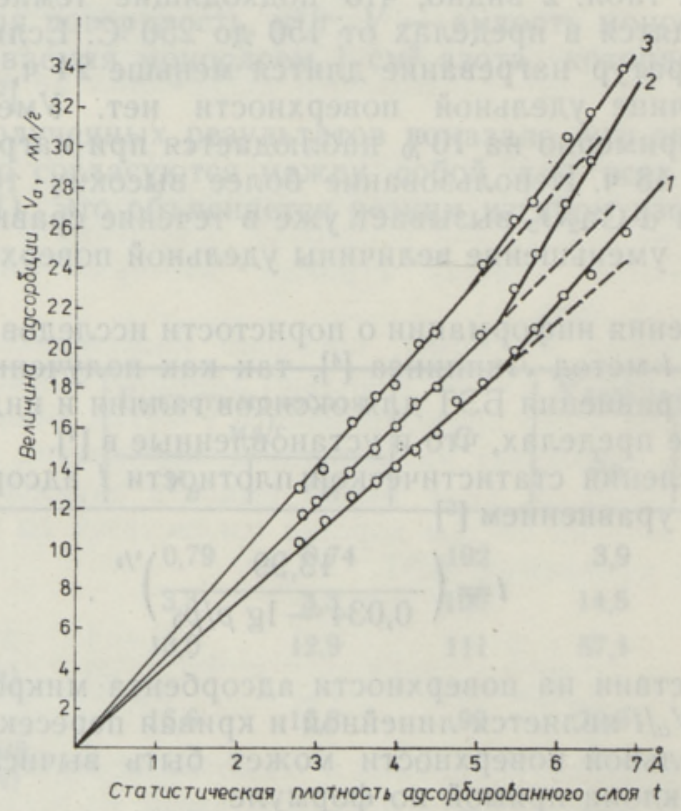

Рис. 3. $V_{a} / \mathrm{t}$-кривые адсорбции азота на $\alpha-\mathrm{Ga}_{2} \mathrm{O}_{3}$ годичной выдержки $(1)$, на свежеприготовленном и подвергнутом дегазации в течение 48 ч (2) и 24 ч (3). 
Расположение адсорбционной кривой выше $t$-кривой говорит о наличии капиллярной конденсации, т. е. адсорбент набирает на свою поверхность больше адсорбата, чем требуется для заполнения монослоя [6].

Для исследованных образцов $\alpha$-модификации оксида галлия капиллярная конденсация начинается при относительных давлениях $p / p_{0}=$ $=0,3-0,4$. Вычисленные значения $S_{t}$ и $S_{\text {Бэт }}$ отличаются не более чем на $2 \%$.

\section{Л И Т Е Р А Т У Р А}

1. Грег С., Синг К. Адсорбция, удельная поверхность, пористость. М., 1970, 68.

2. Huang, C. P., Stumm, W. The specific surface area of $\mathrm{Al}_{2} \mathrm{O}_{3}$. - Surface Sci., 1972, $32, \mathrm{~N} 2,287-296$.

3. Брунауэр С. Адсорбция газов и паров, І. М., 1948, 139-194.

4. Boer, J. H. de, Lippens, B. C., Linsen, B. C., Brokholf, J. C. P., Heuvel, A. A. van den, Osinga, Th. J. The $t$-curve of multimolecular $\mathrm{N}_{2}$ adsorption. - J. Colloid and Interface Sci., 1966, 21, 405-414.

5. Boer, J. H. de, Linsen, B. G., Osinga, Th. J. Studies on pore systems in catalysts. J. Catal., 1965, 4, 643-648.

6. Lippens, B. S., Boer, J. H. de. Studies on pore systems in catalysts. - J. Catal., 1965, 4, $319-323$.
Ннститут термофизики и электрофизики Академии наук Эстонской ССР
Поступила в редакцию 27/I 1987

\section{Virginia ARRO, I. ARRO}

\section{LAMMASTIKU MADALATEMPERATUURILISE ADSORPTSIOONI UURIMINE INDIUM- JA GALLIUMOKSIIDIDEL}

Lämmastiku madalatemperatuurilise adsorptsiooni uurimine galliumoksiidi $\alpha$ - ja $\beta$ modifikatsioonidel ning indiumoksiidil näitas, et saadud tulemustest eripinna arvutamine BET-meetodil ning Lippensi $t$-meetodil annab praktiliselt ühtelangevad tulemused. Värskelt valmistatud $\alpha-\mathrm{Ga}_{2} \mathrm{O}_{3}$ eripind oli vastavalt 73,8 ja $73,1, \beta-\mathrm{Ga}_{2} \mathrm{O}_{3}-14,5$ ja 14,9 ning $\mathrm{In}_{2} \mathrm{O}_{3}-3,2$ ja $3,2 \mathrm{~m}^{2} / \mathrm{g}$. Kasutades $t$-meetodit on tuvastatud, et $\alpha-\mathrm{Ga}_{2} \mathrm{O}_{3}$, mis on saadud galliumnitraadi lagundamisel temperatuuril $400-450{ }^{\circ} \mathrm{C}$, on poorne. $\alpha-\mathrm{Ga}_{2} \mathrm{O}_{3}$ eripind väheneb pikaajalisel seismisel normaalsetes laboratoorsetes tingimustes, samuti ka kuumutamisel $\left(250^{\circ} \mathrm{C}\right)$ kuni $25 \%$.

\section{Virginia ARRO, I. ARRO}

\section{INVESTIGATION OF THE LOW TEMPERATURE ADSORPTION OF NITROGEN ON INDIUM AND GALLIUM OXIDES}

The results in studying the low temperature adsorption of $\alpha$ - and $\beta$-modifications of $\mathrm{Ga}_{2} \mathrm{O}_{3}$ have shown that the value of specific surface areas calculated by BET method and the Lippens $t$-method agree well. The specific surface area of fresh $\alpha-\mathrm{Ga}_{2} \mathrm{O}_{3}$ was 73.8 and $73.1 ; \beta-\mathrm{Ga}_{2} \mathrm{O}_{3} 14.5$ and $14.9 ; \quad \mathrm{In}_{2} \mathrm{O}_{3} 3.2$ and $3.2 \mathrm{~m}^{2} / \mathrm{g}$, respectively. It has been determined by the $t$-method that $\alpha-\mathrm{Ga}_{2} \mathrm{O}_{3}$ prepared by the decomposition of gallium nitrate at $400-450{ }^{\circ} \mathrm{C}$ is porous. The specific surface area of $\alpha-\mathrm{Ga}_{2} \mathrm{O}_{3}$ decreases considerably (up to $25 \%$ ) at room temperature during its shelf life and by heating it (over $250^{\circ} \mathrm{C}$ ). 